\title{
Temperature-Dependent Multidimensional Self-Assembly of Polyphenylene-Based "Rod-Coil” Graft Polymers
}

\author{
Yinjuan Huang ${ }^{1}$ Yiyong Mai ${ }^{1 *}$, Xiangwen Yang, Uliana Beser ${ }^{2}$, Junzhi Liu², Fan Zhang ${ }^{1}$ Deyue \\ Yan $^{1}$, Klaus Müllen ${ }^{2}$, Xinliang Feng ${ }^{1,3 *}$ \\ ${ }^{1}$ School of Chemistry and Chemical Engineering, Shanghai Jiao Tong University, 8oo Dongchuan RD, Shanghai \\ 200240, P. R. China \\ ${ }^{2}$ Max Planck Institute for Polymer Research, Ackermannweg 10, 55128, Mainz, Germany \\ ${ }^{3}$ Department of Chemistry and Food Chemistry, Technische Universität Dresden, Mommsenstrasse 4, 01062 Dres- \\ den, Germany
}

Supporting Information

\begin{abstract}
We present a novel type of "rod-coil" graft copolymer containing a polyphenylene backbone linked with poly(ethylene oxide) (PEO) side chains. Such graft copolymers manifest unprecedented temperature-dependent onedimensional $(\mathrm{l} \mathrm{D})$ and two-dimensional $(2 \mathrm{D})$ self-assembly in solution. At $20^{\circ} \mathrm{C}$ that is higher than the crystallization temperature $\left(T_{\mathrm{c}}\right)$ of the PEO chains, the achiral graft copolymers self-organize into nanoribbons that twist into $\sim 30 \mu \mathrm{m}$ ultralong helices with controlled pitch depending on the grafting ratio of the $\mathrm{PEO}$ chains. At $10^{\circ} \mathrm{C}$, which is lower than the $T_{\mathrm{c}}$, quadrangular multilayer sheets of over $10 \mu \mathrm{m}$ in lateral size are obtained. To our knowledge, this work presents the first example of controlled self-assembly of graft polymers into $1 \mathrm{D}$ helix and $2 \mathrm{D}$ sheet superstructures.
\end{abstract}

The supramolecular nanostructures of conjugated polymers with rigid backbones, ${ }^{1}$ e.g., polyphenylene and polythiophene, have attracted considerable interest, owing to their unique electronic and optoelectronic properties. ${ }^{1-7}$ In general, "rod-coil" conjugated polymers with both rigid conjugated and flexible polymer sequences can be synthons for self-assembly, the two primary types of which are "rodcoil" block copolymers and "rod-coil" graft copolymers. The self-assembly of "rod-coil" block copolymers has been extensively investigated in the past and various ordered nanostructures, including spheres, cylinders, and vesicles, have been achieved..$^{2-7}$ For instance, Park and co-workers reported the self-assembly of a polythiophene-based "rod-coil" block copolymer, namely poly[3-(2,5,8,11-tetraoxatridecanyl)thiophene]-block-poly(ethylene glycol), resulting in ribbons and vesicles in tetrahydrofuran (THF)-water solutions depending on the water content. ${ }^{7}$ In contrast, although the selfassembly of "rod-coil" graft copolymers, which comprise a rigid conjugated backbone with densely tethered polymeric side chains, ${ }^{8}$ has been also studied in recent years, ${ }^{9}$ it remains much less explored in many respects, including morphological control, hierarchical self-assembly, etc.

Herein, we demonstrate a novel type of "rod-coil" graft copolymer containing an expanded poly-para-phenylene backbone grafted with poly(ethylene oxide) (PEO) side chains (Figure 1). Featuring a unique "rod-coil" structure with a short average distance between neighboring PEO chains on the conjugated backbone, such graft copolymers exhibit remarkable temperature-dependent $1 \mathrm{D}$ and $2 \mathrm{D}$ hierarchical self-assembly behavior in solution above $\left(20^{\circ} \mathrm{C}\right)$ and below $\left(10^{\circ} \mathrm{C}\right.$ ) the $T_{\mathrm{c}}$ of the PEO chains, respectively. During the $\mathrm{iD}$ self-assembly, the achiral graft copolymers organized into nanoribbons, which further bundled into ultralong helices with controlled pitch depending on the grafting ratio of the PEO chains (Figure $1 \mathrm{~A}$ ). The $2 \mathrm{D}$ self-assembly of the graft copolymers resulted in quadrangular multilayer sheets of micrometer-sized lateral dimensions (Figure $1 B$ ), for which an unprecedented self-assembly process from nanoribbons to "raft-like" nanostructures and, eventually, to the sheets was observed. To the best of our knowledge, such graft polymers represent the first example of polymers that can selectively self-assemble into $1 \mathrm{D}$ helix and $2 \mathrm{D}$ sheet superstructures.

To prepare the "rod-coil" graft copolymers, laterally expanded poly-para-phenylene (i.e. poly-para-phenylene with dendritic tetraphenylbenzene substituents) decorated with $\mathrm{C}_{10} \mathrm{H}_{20} \mathrm{COOCH}_{3}\left(\mathrm{PP}-\mathrm{COOCH}_{3}\right)$ was first synthesized by the Yamamoto polymerization of a dichloro-substituted oligophenylene monomer (Figure 1 and Section 3 in the Supporting Information). After the hydrolysis of $\mathrm{PP}-\mathrm{COOCH}_{3}$ to $\mathrm{PP}-\mathrm{COOH}$, the graft copolymers were synthesized by the esterification of the carboxyl groups on $\mathrm{PP}-\mathrm{COOH}$ with the hydroxyl groups at one end of $1 \mathrm{~K} \mathrm{~g} / \mathrm{mol}$ PEO (Figure 1). The successful grafting of the PEO chains onto the polyphenylene was validated by Fourier transform infrared spectroscopy (FTIR) (Figure S17) and nuclear magnetic resonance (NMR) analyses (Figure S18). Table 1 presents three graft copolymers with different grafting percentages (GPs) of PEO chains, namely GC-91, GC- 55 and GC-28, with GPs of $91 \%, 55 \%$ and $28 \%$, respectively, as determined by NMR and supported by calculations based on element analyses (Pages S16-17). Gel permeation chromatography (GPC) results showed increased number-average molecular weights $\left(M_{\mathrm{n}}\right)$ compared with that of $\mathrm{PP}_{-} \mathrm{COOCH}_{3}$ (Table 1). The $M_{\mathrm{n}}$ values measured by GPC $\left(M_{\mathrm{n}, \mathrm{GPC}}\right)$ are slightly smaller than the calculated values $\left(M_{\mathrm{n}, \text { calc }}\right)$ based on the $M_{\mathrm{n}}$ of PP-COOCH $\mathrm{C}_{3}$ and the GPs. This difference is likely caused by the presence of carboxyl groups 
in the graft polymers, which enhance the adsorption of the polymers on GPC column and thus prolong their exclusion. ${ }^{10}$

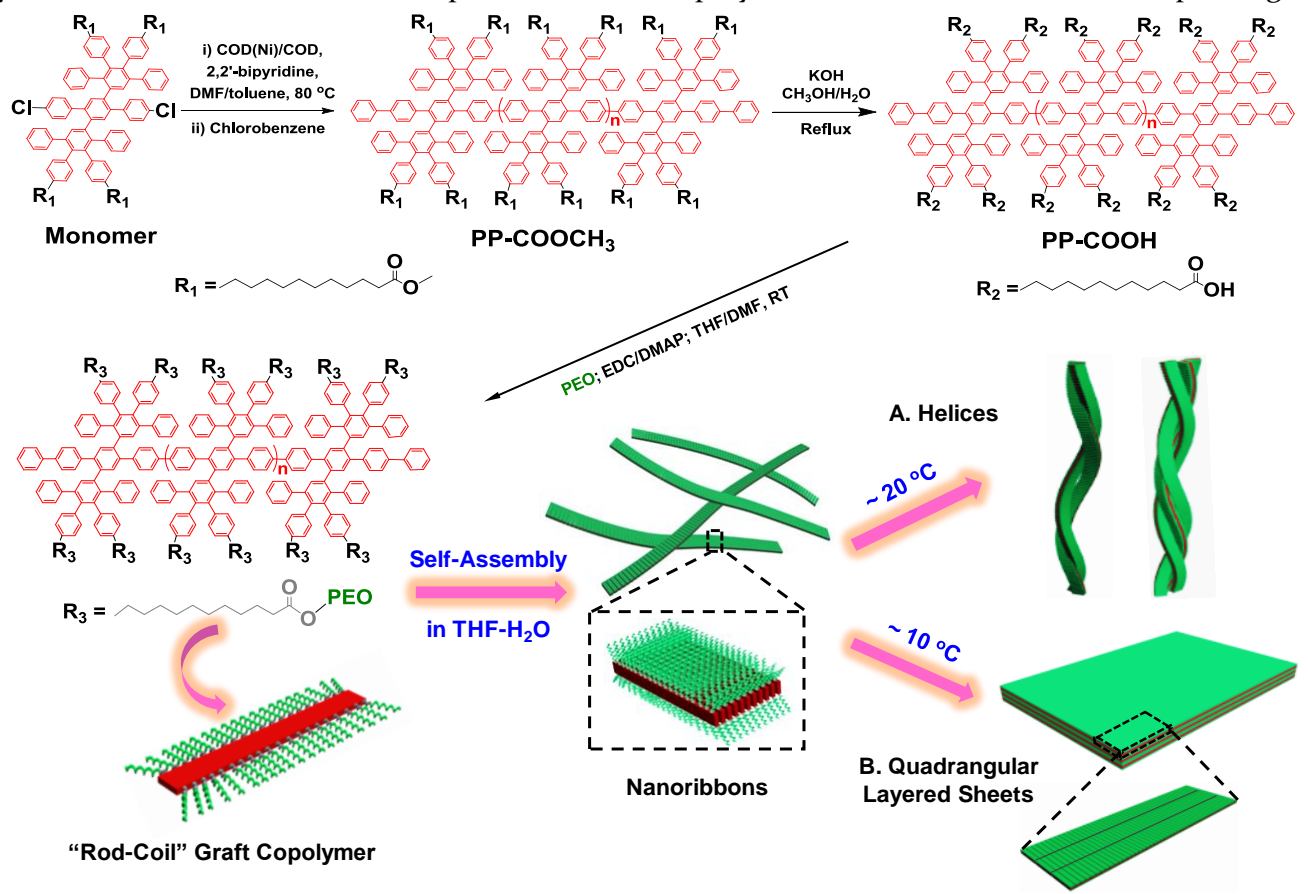

Figure 1. Schematic illustration of the synthesis of "rod-coil" graft copolymers containing a polyphenylene backbone grafted with PEO side chains as well as the temperature-dependent $1 \mathrm{D}$ and $2 \mathrm{D}$ hierarchical self-assembly process.

The self-assembly of the "rod-coil" graft copolymers was performed through a co-solvent method $^{11}$ at different temperatures by considering the $T_{\mathrm{c}}$ of the tethered PEO chains (see below). Briefly, the copolymers were dissolved in THF, which is a common solvent for both polyphenylene and PEO, to produce a $10^{-3} \mathrm{mg} \mathrm{mL}^{-1} \mathrm{THF}$ solution; under stirring, the solution was added dropwise $\left(0.06 \mathrm{~mL} \mathrm{~min}^{-1}\right.$ ) to a 4 -fold amount of pure water, a selective solvent for PEO. The mixed solution turned from colorless to light blue, suggesting the formation of polymer aggregates.

\section{Table 1. NMR and GPC Data for the Graft Copolymers}

$\begin{array}{lllll}\text { Name } & \text { GP }(\%)^{a} & M_{\text {n, calc }}{ }^{b} & M_{\text {n, GPC }}{ }^{c} & \text { PDI }^{c} \\ \text { PP-COOCH } & \text { N/A } & \text { N/A } & 21,400 & 1.13 \\ \text { GC-91 } & 91 & 65,100 & 57,600 & 1.31 \\ \text { GC-55 } & 55 & 47,800 & 42,100 & 1.27 \\ \text { GC-28 } & 28 & 34,800 & 26,000 & 1.25\end{array}$

${ }^{a}$ PEO grafting percentages measured by NMR. ${ }^{b}$ Calculated molecular weights based on $M_{\mathrm{n}}$ (GPC, PP-COOCH$H_{3}$ ) and GPs. ${ }^{c} M_{\mathrm{n}}$ and polydispersity index (PDI) measured by GPC against a polystyrene standard; GPC curves are given in Figures $\mathrm{S}_{15}$ and S19.

The self-assembly of GC-91 in the THF-water solution at $20{ }^{\circ} \mathrm{C}$ generated long helical nanostructures (Figure 2 and Figure S20). The transmission electron microscopy (TEM) samples prepared by freeze-drying gave the same helical structures as those in the vacuum-dried TEM samples, indicating the formation of helices in solution state. ${ }^{12}$ Statistics based on 200 helices in the TEM images yielded an average diameter $(D)$ of $44 \pm 9 \mathrm{~nm}$ (Figure $2 \mathrm{~A}$ ) and lengths of 10 30 $\mu \mathrm{m}$ (up to $\sim 30 \mu \mathrm{m}$, Figure S2oA and B). Most of the helices comprised two or three $\sim 15 \mathrm{~nm}$ wide $1 \mathrm{D}$ aggregates (Figure $2 \mathrm{~B}$ and $\mathrm{C}$ ); a minority of the helices (<10 number \%) was multistranded ( $\geq 4$ strands) (Figure S2oD and E). High-resolution TEM (HRTEM) images revealed a ribbon-like structure of the
$1 \mathrm{D}$ aggregates of $\sim 15 \mathrm{~nm}$ width. For example, Figure $2 \mathrm{D}$ presents an HRTEM image of a double-stranded helix with a short untwisted section, in which the "width" of one strand is only $\sim 4 \mathrm{~nm}$, much smaller than that $(\sim 15 \mathrm{~nm})$ of the other one. This exceptionally narrow "width" is attributed to the fact that a $4 \mathrm{~nm}$ thick ribbon is located vertically to the substrate under TEM investigation (inset of Figure 2D). As no chiral molecules were used in the self-assembly process, the coexistence of left- and right-handed helices observed by TEM is not surprising. Remarkably, the average diameter and pitch of the helices are tunable by varying the GP of the PEO chains. The statistics indicates that as the GP of PEO decreases from $91 \%$ to $55 \%$ or $28 \%$, the average diameter of the resultant helices decreases from $44 \pm 9 \mathrm{~nm}$ to $39 \pm 3 \mathrm{~nm}$ and $32 \pm 2 \mathrm{~nm}$, along with a decrease in the average pitch from $286 \pm 31 \mathrm{~nm}$ to $208 \pm 33 \mathrm{~nm}$ and $136 \pm 20 \mathrm{~nm}$, respectively (Figure S21).

The helical structure of the GC-91 aggregates was confirmed by atomic force microscopy (AFM) (Figure $2 \mathrm{E}$ ). To further probe the composition of the helices, we attempted to disassemble the helices by strong sonication of their solutions. AFM profiles manifested that the helices consisted of ribbon-like aggregates with a width of $\sim 15 \mathrm{~nm}$ and a thickness of $\sim 2.6 \mathrm{~nm}$ (Figure $2 \mathrm{~F}$ ). These two values are very close to the calculated length $(\sim 15 \mathrm{~nm})$ and width $(\sim 3.9 \mathrm{~nm})$ of a graft copolymer molecule, respectively, suggesting that the ribbon-like aggregates are formed by the parallel alignment of the graft copolymers (see Section 4.3.1, Page S23).

In light of the above-mentioned results, in particular, the dimensions of the graft copolymer molecules and the resultant aggregates, we suggest a possible self-assembly mechanism, as illustrated in Figure 1. Driven by the hydrophobic interaction, the graft copolymers first self-assemble into $\sim 15$ $\mathrm{nm}$ wide and $\sim 2.6 \mathrm{~nm}$ thick nanoribbons with a hydrophobic polyphenylene layer sandwiched by hydrophilic PEO coils. 
Owing to the relatively low PEO number density at both edges of the nanoribbons, they tend to associate to minimize the polyphenylene-water contact. However, the average distance between adjacent PEO chains in GC-91, GC-55, or GC-28 in the nanoribbons is estimated to be $\sim 0.7, \sim 1.2$, or $\sim 2.2 \mathrm{~nm}$, respectively (see Section 4.3.2, Pages S24-25). These distances are smaller than twice the radius of gyration $\left(R_{\mathrm{g}}=\right.$ $\sim 1.5 \mathrm{~nm}$ ) of a $1 \mathrm{~K} \mathrm{~g} / \mathrm{mol}$ PEO chain at its end-free state in solution, ${ }^{13}$ suggesting the existence of crowded PEO coils around the associated nanoribbons. Thus, the steric interaction among the PEO chains may cause a twist of the associated nanoribbons providing more peripheral space for the PEO coils and lead to the formation of $1 \mathrm{D}$ helical superstructures (Figure S22). The peripheral space around a helix within a small pitch can accommodate only a relatively small number of PEO chains; hence, with an increase in the PEO grafting ratio, the pitch of the helices increases accordingly.

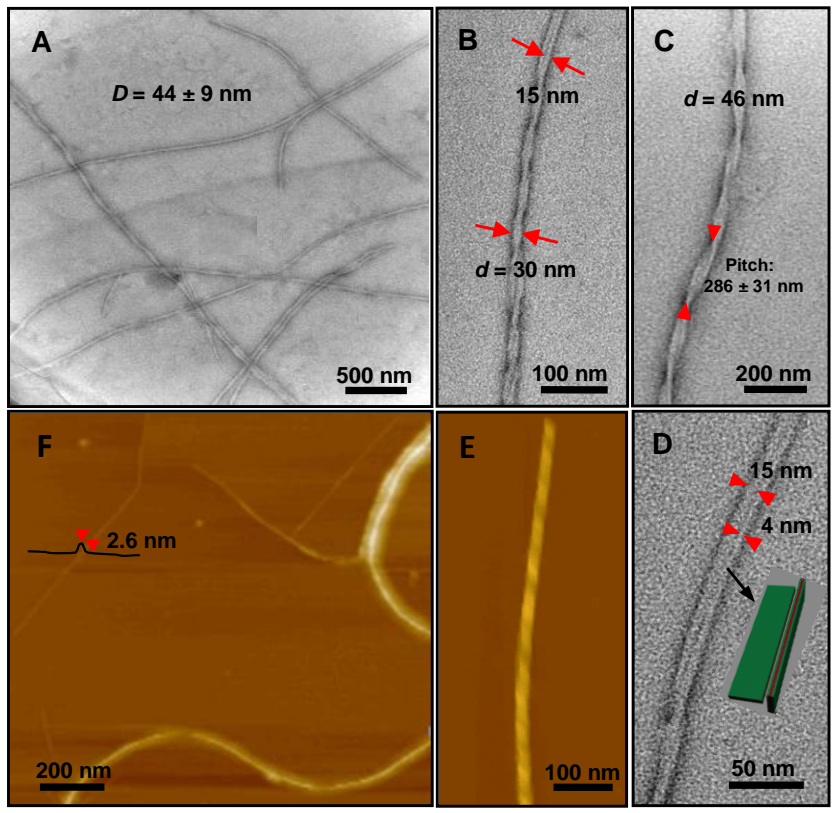

Figure 2. TEM and AFM images of the helices formed by the hierarchical self-assembly of the GC-91 graft copolymers in THF-water (v/v 4:1) at $20{ }^{\circ} \mathrm{C}$. (A) A low-magnification TEM image of the helices $(D$ denotes the average diameter); (B, C) high-magnification TEM images of the double- and triple-stranded helices with related sizes indicated ( $d$ expresses a diameter of a specific helix); (D) an HRTEM micrograph of an untwisted region in a double-stranded helix, in which a ribbon-like aggregate is positioned vertical to the substrate (inset); (E) an AFM height profile of a helix; (F) an AFM height image scanned after strong sonication of the helix dispersion in THF-water.

Although supramolecular helix formation has been found in a few achiral linear polymers, ${ }^{3,14}$ the current study presents the first example of helix formation by achiral graft polymers. More interestingly, we found that the graft copolymers selforganized into free-standing $2 \mathrm{D}$ quadrangular multilayer sheets at $10{ }^{\circ} \mathrm{C}$. The sheet formation occurred over a period of days, with the aging of the as-prepared solution of the GC-91 aggregates at $10^{\circ} \mathrm{C}$. Within $5 \mathrm{~h}$ of aging, TEM images (Figure $3 \mathrm{~A}$ ) revealed a large number of raft-like assemblies (called "rafts") that consisted of $\sim 15 \mathrm{~nm}$ wide $1 \mathrm{D}$ nanostructures (inset of Figure $3 \mathrm{~A}$ ); the width was similar to that of the above-discussed nanoribbons. Moreover, the thickness of the "rafts" was $\sim 2.6 \mathrm{~nm}$ (Figure $3 \mathrm{~B}$ ), the same as that of the nanoribbons. Therefore, it is reasonable to believe that the "rafts" are single-layered and formed by the planar alignment of the nanoribbons. Remarkably, with the aging of the solution, the "rafts" grew to narrow nanosheets (Figure ${ }_{3} \mathrm{C}$ and $\mathrm{D}$ ) and eventually to quadrangular sheets after ca. 10 days (Figure $3 \mathrm{E}-\mathrm{H})$. The thickness of the quadrangular sheets was greater than that of the "rafts", suggesting a multilayer feature of the sheets. The quadrangular sheets suspended in solution were also observed by optical microscopy (Figure S23), confirming that the sheets were formed in solution. On the other hand, dynamic light scattering (DLS) analyses revealed an obvious increase in the hydrodynamic diameter of the GC-91 assemblies with the aging of the solution at $10^{\circ} \mathrm{C}$, whereas no big change was found in the hydrodynamic size of the GC-91 helices in solution at $20^{\circ} \mathrm{C}$ (Figure $\mathrm{S}_{24}$ ). The results confirm the gradual growth of the GC-91 assemblies in solution at $10{ }^{\circ} \mathrm{C}$.

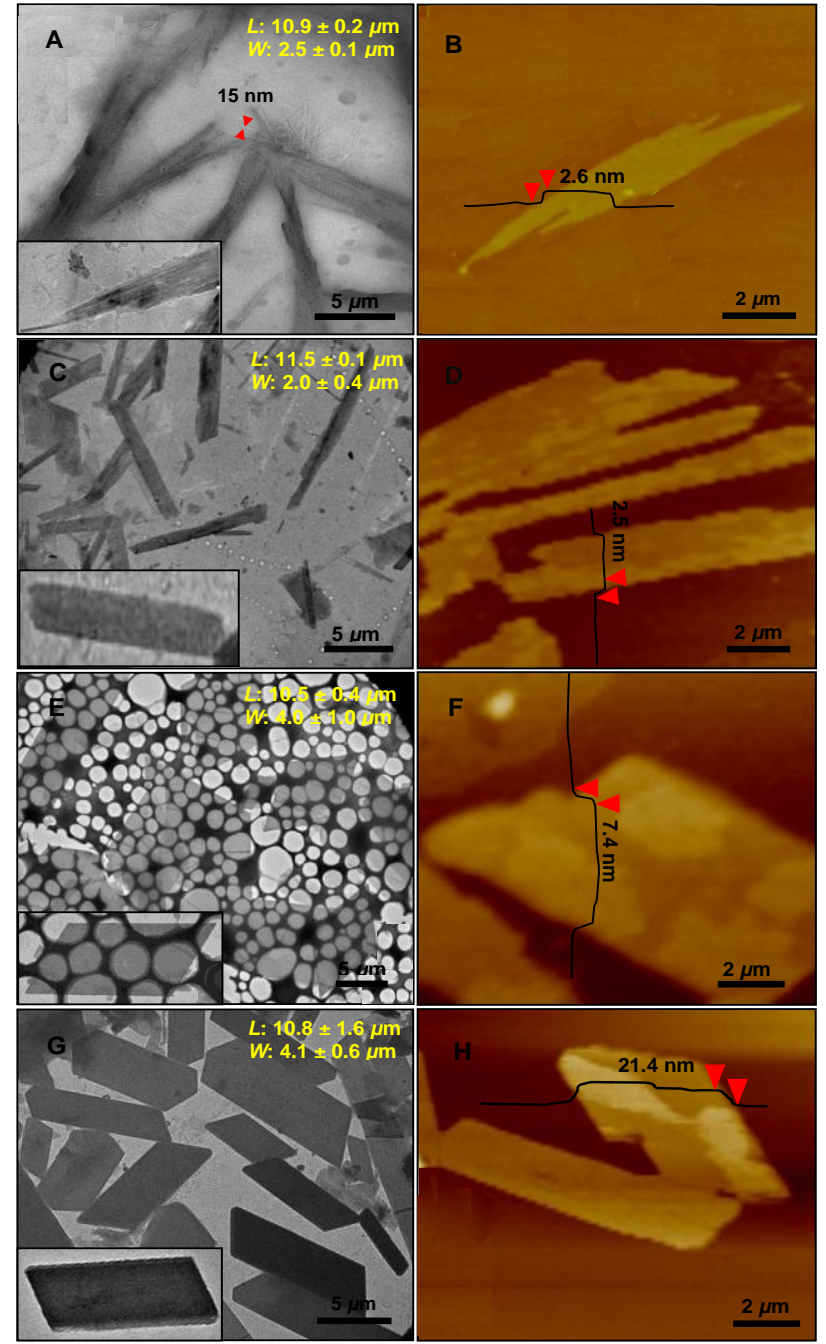

Figure 3. TEM and AFM images of the $2 \mathrm{D}$ aggregates formed by the hierarchical self-assembly of GC-91 in THF-water (v/v 4:1) at $10{ }^{\circ} \mathrm{C}$ after (A, B) 5 h, (C, D) 1 days, (E, F) 5 days, and (G, H) 10 days. The average lengths $(\mathrm{L})$, widths $(\mathrm{W})$, and thicknesses of the aggregates are indicated in the corresponding TEM and AFM images.

It is known that PEO crystallization in organic media may contribute to the solution growth of multilayer rhombus crystals of some PEO-containing block copolymers, e.g., PEO- $b$-polycaprolactone in hexanol. ${ }^{15,16}$ In the present study, 
differential scanning calorimetry (DSC) analyses of GC-91 revealed a $T_{\mathrm{c}}$ of $\sim 16^{\circ} \mathrm{C}$ for the grafted $1 \mathrm{~K} \mathrm{~g} / \mathrm{mol}$ PEO chains (Figure $\mathrm{S}_{25} \mathrm{~A}$ ). Micro-DSC measurements gave a $T_{\mathrm{c}}$ of $\sim 13{ }^{\circ} \mathrm{C}$ for the PEO chains in the GC-91 aggregates in THF-water (Figure $\mathrm{S}_{25} \mathrm{~B}$ ). Apparently, the $1 \mathrm{D}$ and $2 \mathrm{D}$ self-assembly of GC-91 occurred above and below the $T_{\mathrm{c}}$ of the PEO chains, respectively. After GC-91 self-organized into nanoribbons (Figure 1), a short average distance of $\sim 0.7 \mathrm{~nm}$ between neighboring $\mathrm{PEO}$ chains on the polyphenylene backbone resulted in a high number density of PEO chains at the ribbon surface, which exceeded the onset density for the crystallization of the chains below their $T_{c}$ (see calculations in Section 4.3.2, Pages S24-25). ${ }^{16,17}$ Thus, the crystallization and the resulting compact state of the PEO chains may favor the transformation of the nanoribbons into sheet-like structures. $^{18}$ In contrast, the PEO chains at the surfaces of the nanoribbons formed by GC-55 or GC-28 cannot crystallize due to the low density of the chains (Section 4.3.2, Pages S24$25),{ }^{16,17}$ which accounts for the formation of only helices rather than sheets under similar experimental conditions. As the onset density of PEO crystallization is determined by both the dimension of PEO and the average distance between neighboring PEO chains on the polyphenylene, the length of PEO chains, in addition to the GP, can also affect the $2 \mathrm{D}$ self-assembly of the graft copolymers. For instance, owning a GP of $\sim 90 \%$, the graft copolymer with $500 \mathrm{~g} / \mathrm{mol}$ PEO side chains did not form quadrangular multilayer sheets under similar conditions, due to the reduced length of the PEO coils.

To further investigate how the multilayer sheets are related to the crystallization of the PEO chains, the THF-water solution of the sheets was dialyzed against water to remove THF at $10{ }^{\circ} \mathrm{C}$. Interestingly, we found that the multilayer sheets developed into "rafts" after the removal of the THF (Figure S26A and B). Increasing the temperature of the THFwater solution from 10 to $25{ }^{\circ} \mathrm{C}$ also yielded "rafts". Such disorganization, the reverse step of the sheet formation, may be caused by the expansion of the PEO coils in solution from a compact crystalline state in the presence of organic media (THF in this case) or below their $T_{\mathrm{c}}{ }^{16,18}$ Moreover, an attempt was made to elucidate the crystal structure of the sheets by electron diffraction (ED). However, no diffraction patterns were observed (Figure S26C), probably due to the destruction of the crystal structure at temperatures higher than the $T_{\mathrm{c}}$ of the $1 \mathrm{~K} \mathrm{~g} / \mathrm{mol} \mathrm{PEO}$ upon the irradiation of electron beams. ${ }^{19}$
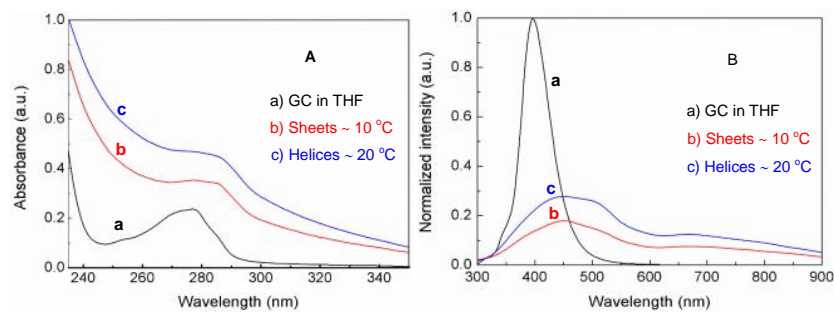

Figure 4. (A) UV-vis and (B) photoluminescence spectra of GC-91 in THF as well as of the helices and the sheets in THF-water (v/v 4:1) at different temperatures (concentration: $2 \times 10^{-4} \mathrm{mg} \mathrm{mL}^{-1}$ ).

The optical properties of the GC-91 assemblies in THFwater solutions were studied by ultraviolet-visible (UV-vis) and photoluminescence (PL) spectroscopies (Figure 4). The maximum absorption of the helices and the sheets were redshifted to $290 \mathrm{~nm}$, compared with $280 \mathrm{~nm}$ of GC-91 in THF
(Figure $4 \mathrm{~A}$ ), indicative of intermolecular $\pi-\pi$ interactions associated with the aggregation of GC-91. ${ }^{3}$ The PL spectra revealed a distinct quenching of the photoluminescence of both the helices and the sheets in THF-water (Figure $4 \mathrm{~B}$ ). The PL spectra of the helices remained almost unchanged with the aging of their solution at $20^{\circ} \mathrm{C}$ over 10 days, suggesting their good stability in solution; ${ }^{3}$ however, the PL spectra of the assemblies obtained at $10{ }^{\circ} \mathrm{C}$ showed a consecutive quenching of the photoluminescence (Figure S27), most probably due to the progressive formation of the sheets.

In summary, we prepared a novel type of "rod-coil" graft copolymer containing a poly-para-phenylene backbone grafted with $1 \mathrm{~K} \mathrm{~g} / \mathrm{mol}$ PEO chains. Remarkably, these polymers performed temperature-dependent $1 \mathrm{D}$ and $2 \mathrm{D}$ selfassembly in solution. At $20{ }^{\circ} \mathrm{C}$ that is above the $T_{\mathrm{c}}$ of the PEO chains, the achiral graft copolymers self-organized into $1 \mathrm{D}$ nanoribbons that further bundled into $\sim 30 \mu \mathrm{m}$ helices. At $10{ }^{\circ} \mathrm{C}$ which is below the $T_{\mathrm{c}}$, the self-assembly of the graft copolymers, driven by the crystallization of the tethered PEO chains, resulted in progressive growth of nanoribbons into "rafts" and eventually into quadrangular multilayer sheets with lateral dimensions of over $10 \mu \mathrm{m}$. These novel "rod-coil" graft polymers provide new opportunities for the controlled preparation of $1 \mathrm{D}$ helix and $2 \mathrm{D}$ superstructures as well as offer a new system for the fundamental studies on the selfassembly of conjugated polymers, including morphological control, thermodynamics and kinetics, and potential applications, etc.

\section{ASSOCIATED CONTENT}

\section{Supporting Information}

Experiments, supporting figures and calculations, etc. This material is available free of charge via the Internet at http://pubs.acs.org

\section{AUTHOR INFORMATION}

\section{Corresponding Authors}

mai@sjtu.edu.cn; xinliang.feng@tu-dresden.de

\section{Notes}

The authors declare no competing financial interest.

\section{ACKNOWLEDGMENTS}

The authors thank the financial support from the 973 Programs of China (2012CB933404 and 2013CBAo16o2), the Natural Science Foundation of China (21320102006 and 21304057), the Natural Science Foundation of Shanghai (13ZR1421200), the Program for Eastern Scholar in Shanghai, and the MPI Partner Group Project for Polymer Chemistry of Graphene Nanoribbons. We also thank the Instrumental Analysis Center of Shanghai Jiao Tong University for some measurements.

\section{REFERENCES}

(1) (a) Li, C.; Liu, M.; Pschirer, N. G.; Baumgarten, M.; Müllen, K. Chem. Rev. 2010, 110, 6817; (b) Bonillo, B.; Swager, T. M. J. Am. Chem. Soc. 2012, 134, 18916; (c) Liu, J.; Li, B.; Tan, Y.; Giannakopoulos, A.; Sanchez-Sanchez, C.; Beljonne, D.; Ruffieux, P.; Fasel, R.; Feng, X.; Müllen, K. J. Am. Chem. Soc. 2015, 137, 6097.

(2) Jenekhe, S. A.; Chen, X. L. Science 1998, 279, 1903. 
(3) Lee, E.; Hammer, B.; Kim, J.-K.; Page, Z.; Emrick, T.; Hayward, R. C. J. Am. Chem. Soc. 2011, 133, 10390.

(4) Patra, S. K.; Ahmed, R.; Whittell, G. R.; Lunn, D. J.; Dunphy, E. L.; Winnik, M. A.; Manners, I. J. Am. Chem. Soc. 2011, 133, 8842.

(5) Zheng, Y.; Zhou, H.; Liu, D.; Floudas, G.; Wagner, M.; Koynov, K.; Mezger, M.; Butt, H.-J.; Ikeda, T. Angew. Chem. Int. Ed. 2013, 52, 4845 .

(6) Liu, N.; Qi, C. G.; Wang, Y.; Liu, D. F.; Yin, J.; Zhu, Y. Y.; Wu, Z. Q. Macromolecules 2013, 46, 7753 .

(7) Kamps, A. C.; Cativo, M. H. M.; Fryd, M.; Park, S.-J. Macromolecules, 2014, 47, 161.

(8) (a) Sheiko, S. S.; Sumerlin, B. S.; Matyjaszewski, K. Prog. Polym. Sci. 2008, 33, 759; (b) Rzayev, J. ACS Macro Lett. 2012, 1, 1146.

(9) (a) Yao, J. H.; Mya, K. Y.; Shen, L.; He, B.; Li, L.; Li, Z.; Chen, Z.; Li, X.; Loh, K. P. Macromolecules 2008, 41, 1438; (b) Lin, J.; Zhu, G.; Zhu, X.; Lin, S.; Nose, T.; Ding, W. Polymer 2008, 49, 1132; (c) Cai, C.; Lin, J.; Chen, T.; Tian, X. Langmuir 2010, 26, 2791; (d) Miyake, G. M.; Weitekamp, R. A.; Piunova, V. A.; Grubbs, R. H. J. Am. Chem. Soc. 2012, 134, 14249.

(10) Turner, S. R.; Walter, F.; Voit, B. I.; Mourey, T. H. Macromolecules 1994, 27, 1611 .
(11) Mai, Y.; Eisenberg, A. Chem. Soc. Rev. 2012, 41, 5969.

(12) Azzam, T.; Eisenberg, A. Langmuir 2010, 26, 10513.

(13) The $R_{\mathrm{g}}$ for a PEO chain at its end-free state in solution is estimated using $R_{\mathrm{g}}{ }^{2}=b^{2} N_{\mathrm{b}} / 6$ from: Rubenstein, M.; Colby, R. H. Polymer Physics; Oxford University Press: New York, 2004, where $b=0.8 \mathrm{~nm}$ for PEO.

(14) (a) Zhang, S.; Cui, H.; Chen, Z.; Wooley, K. L.; Pochan, D. J. Soft Matter 20o8, 4, 90; (b) Dupont, J.; Liu, G.; Niihara, K.-I.; Kimoto, R.; Jinnai H. Angew. Chem. Int. Ed. 2009, 48, 6144.

(15) Sun, J. R.; Chen, X. S.; He, C. L.; Jing, X. B. Macromolecules 2006, 39,3717 .

(16) Van Horn, R. M.; Zheng, J. X.; Sun, H.-J.; Hsiao, M.-S.; Zhang, W.-B.; Dong, X.-H.; Xu, J.; Thomas, E. L.; Lotz, B.; Cheng, S. Z. D. Macromolecules 2010, 43, 6113.

(17) Zheng, J. X.; Xiong, H.; Chen, W. Y.; Lee, K.; Van Horn, R. M.; Quirk, R. P.; Lotz, B.; Thomas, E. L.; Shi, A.-C.; Cheng, S. Z. D. Macromolecules 2006, 39, 641 .

(18) Rizis, G.; van de Ven, T. G. M.; Eisenberg, A. Angew. Chem. Int. Ed. 2014, 53, 9000 .

(19) Egerton, R. F.; Malac, P. Li, M. Micron 2004, 35, 399. 


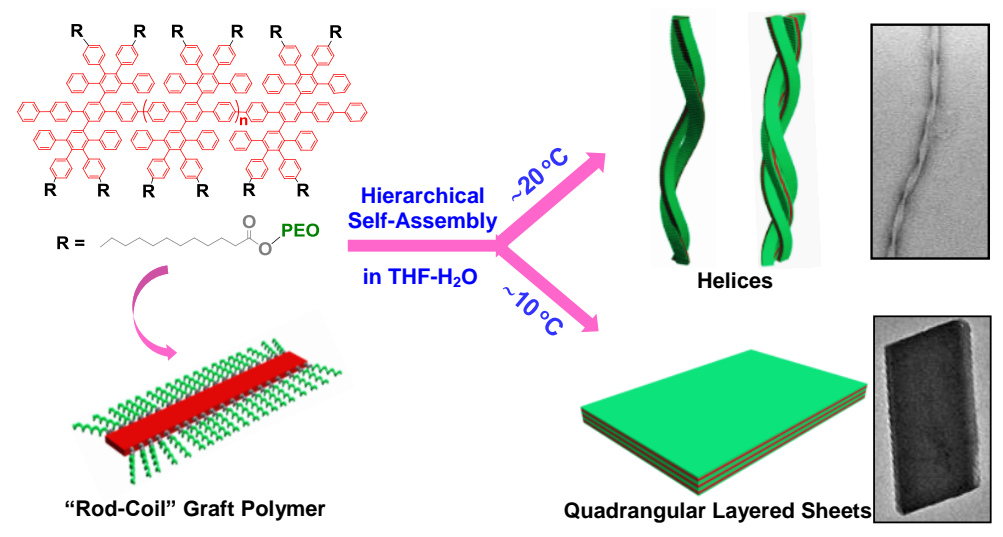

